\title{
Ácido abscísico y sacarosa afectan la formación in vitro de túberos en plantas de ñame (Dioscorea rotundata Poir.)
}

\author{
Abscisic acid and sucrose affect in vitro tuber formation in yam \\ (Dioscorea rotundata Poir.) plants
}

\author{
Isidro E. Suárez ${ }^{1 *}$, Rafael A. Otero ${ }^{2}$ \\ Recibido para publicación: Septiembre 4 de 2015 - Aceptado para publicación: Abril 4 de 2016
}

\begin{abstract}
RESUMEN
El túbero de ñame (Dioscorea rotundata Poir.) es una de las principales fuentes alimenticias de los pobladores de la Costa Atlántica Colombiana y la cuenca del Caribe, y su demanda ha aumentado en el mercado internacional en los últimos años; sin embargo, las técnicas convencionales de cultivo afectan la cantidad y calidad de la producción. Con el fin de ofrecer mecanismos de producción de material de siembra de ñame de buena calidad, se evaluó el efecto de tres concentraciones de sacarosa y cuatro niveles de ácido abscísico en la producción in vitro de microtúberos a partir de explantes nodales. Los tratamientos se distribuyeron con un diseño completamente al azar con ocho repeticiones por tratamiento. El análisis de varianza y la prueba de media de Duncan indicaron que tanto las variables del crecimiento de las plantas como el número de microtúberos mostraron diferencias significativas $(\operatorname{Pr}<0,05)$ como resultado de los niveles de $A B A /$ sacarosa, una dosis de $60 \mathrm{~g}$ $\mathrm{L}^{-1}$ de sacarosa combinada con $3,0 \mathrm{mg} \mathrm{L}^{-1}$ de $\mathrm{ABA}$ indujo el mayor número de microtúberos, mientras que las plantas cultivadas en presencia de $90 \mathrm{~g} \mathrm{~L}^{-1}$ de sacarosa formaron mayor número de tallos, hojas y raíces.
\end{abstract}

Palabras clave: In vitro, túberos, micropropagación, $R C V$, reserva energética.

\begin{abstract}
Yam tuber (Dioscorea rotundata Poir.) is a staple for many populations in the Colombian Atlantic Coastland and the Caribbean basin, and its demand has recently increased in the international market; however, conventional crops practices negatively affect the quantity and quality of production. In order to provide mechanisms for the production of high quality planting material for yam, the effect of three sucrose concentrations combined with four abscisic acid levels on in vitro growing of microtubers from nodal explants was evaluated. Treatments were distributed using a complete randomized design, and the analysis of variance and Duncan's Multiple Range Test showed that plant growth variables as well as microtuber number were significantly affected byABA/sucrose levels. Sucrose dose of $60 \mathrm{~g} \mathrm{~L}^{-1}$ combined with $3.0 \mathrm{mg} \mathrm{L}^{-1}$ of $\mathrm{ABA}$ induced the highest number of microtubers, while plants cultured in a medium supplied with $90 \mathrm{~g} \mathrm{~L}^{-1}$ of sucrose developed more stems, leaves and roots.
\end{abstract}

Key words: In vitro, tubers, micropropagation, PGR, energetic reserve.

\footnotetext{
${ }^{1}$ Ph.D. Universidad de Córdoba, Carrera 6 No. 76-103, Montería-Colombia, Tel: (4) 790 8023, Fax: (4) 7860255. Correo electrónico: isidrosuarez@hotmail.com

${ }^{2}$ Biólogo. Universidad de Córdoba
} 


\section{INTRODUCCIÓN}

El túbero de ñame (Dioscorea rotundata Poir.) constituye una de las principales fuentes alimenticias de muchas poblaciones de las zonas tropicales alrededor del mundo, mientras que en Colombia es considerado como un producto básico dentro de la canasta familiar alimenticia y hace parte de la cultural de los habitantes de la Costa Atlántica. Estudios recientes evidencian el potencial de este producto como fuente de componentes medicinales y su consumo frecuente ha sido relacionado con el mejoramiento y prevención de ciertas condiciones médicas, lo cual asociado a su popularidad en las comunidades latinas y africanas, ha hecho que en los últimos años haya logrado posicionarse comercialmente en el mercado nacional e internacional, principalmente en los Estados Unidos y el Caribe (Perea y Buitrago 2000; Scott et al. 2006; Rêgo et al. 2014; McKoy et al. 2014).

En las sabanas de Córdoba, Sucre y Bolívar los cultivos de ñame convencionalmente se establecen plantando porciones de túberos colectados en cosechas previas. Esta práctica toma como base la selección de un porcentaje de los mejores ejemplares en tamaño, peso y forma, con el fin de obtener un rendimiento sustancial que no conduzca a pérdida de plantas durante las primeras etapas del cultivo. Debido a la estacionalidad del cultivo, la dependencia de los períodos de lluvia en la mayoría de las zonas y el bajo nivel tecnológico de los productores, los túberos separados como material de siembra son almacenados en condiciones poco favorables, lo cual propicia ataques de insectos plagas, enfermedades, roedores y emisión de brotes que impactan negativamente la cantidad y la calidad del material de siembra. Se estima que la toma de túbéros para uso como material de siembra en el establecimiento de próximos cultivos, aunados a las pérdidas en el almacenamiento y etapa de siembra, pueden impactar negativamente hasta un $40 \%$ de la rentabilidad del cultivos tradicionales de ñame de la Costa Atlántica Colombiana (Perea y Buitrago 2000; Cereda 2002; Tamiru et al. 2008).

La microtuberización consiste en la obtención de túberos de tamaño reducido en condiciones in vitro a partir de explantes cultivados en medios de cultivos adicionados con reguladores de crecimiento que favorecen la acumulación masiva de almidones, mediante un cambio en la vía del metabolismo de la sacarosa que los convierte en órganos que durante el período inicial de crecimiento demandan carbohidratos y posteriormente una vez formados sirven de fuente de este recurso (Ondo et al. 2009). Esta respuesta morfológica ha sido foco de estudios para determinar su naturaleza organogenética encontrándose participación de genes con expresión específica en determinados tejidos como el promotor laccase (Jang-Ho et al. 2015), el factor de transcripción StCCD4 (Bruno et al. 2015) y el efecto genéticamente controlado de ácido abscísico (ABA), ácido giberélico (GA) y sacarosa (Muñiz-García et al. 2014) en la inducción, crecimiento y morfología de los túberos en condiciones in vitro.

La búsqueda de mecanismos eficientes para producir material de siembra de excelente calidad para el cultivo de plantas de ñame ha sido fuente de diversas investigaciones (Suárez et al. 2011; Yan et al. 2011; Anike et al. 2012) entre las cuales la microtuberización ha sido intentada como una alternativa ( $\mathrm{Ng}$ 1998; Jean y Cappadocia 1991; Salazar y Beltrán 2003; Acedo et al. 2007; Balogun 2009; Olivier et al. 2012). Con el fin de continuar con la búsqueda de mecanismos para lograr una forma eficiente de producir túberos de ñame en condiciones in vitro, se planteó el presente estudio que tuvo como objetivo principal evaluar el efecto de diferentes concentraciones de sacarosa y ABA en la inducción de microtubérculos y sus características a partir de explantes nodales de D. rotundata. 


\section{MATERIALES Y MÉTODOS}

\section{Material vegetal}

El material vegetal para el presente estudio se obtuvo de plantas de ñame espino (Dioscorea rotundata Poir.) cultivadas in vitro en medio de cultivo de mantenimiento semisólido consistente de $1 / 2$ MS (Murashige y Skoog 1962) suplido con (en $\mathrm{mg} \mathrm{L}^{-1}$ ) sacarosa (30.000), myo-inositol (100), tiamina $\mathrm{HCL}(0,4)$ y solidificado con Phytagel $($ (6.000), Las plantas se mantuvieron por más de un año en $30 \mathrm{ml}$ de medio dispensados en frascos de vidrio de 250 cc de capacidad, cubiertos con papel aluminio y almacenadas a una temperatura de $25^{\circ} \mathrm{C}$ y 12 horas de fotoperíodo $\left(40 \mu \mathrm{mol} \mathrm{m}^{-2} \mathrm{seg}^{-1}\right)$.

\section{Inducción de microtúberos}

Los explantes consistieron de segmentos de aproximadamente $2,0 \mathrm{~cm}$ de longitud con dos nudos, los cuales se establecieron en medio de mantenimiento suplido independientemente con tres concentraciones de sacarosa $(30,60$, $\left.90 \mathrm{~g} \mathrm{~L}^{-1}\right)$ y cuatro concentraciones de ácido abscísico (ABA) (0,0, 1,0, 2,0 y 3,0 $\left.\mathrm{mg} \mathrm{L}^{-1}\right)$. El experimento consistió de un arreglo factorial con 12 tratamientos y 8 repeticiones por cada tratamiento para un total de 96 unidades experimentales distribuidas en un diseño completamente al azar.

El pH del medio de cultivo se ajustó a un valor de 5,7 -5,8 con $\mathrm{KOH}$ o HCL previo a la adición del agente gelificante, se dispensaron cantidades de $30 \mathrm{ml}$ en recipientes de $250 \mathrm{cc}$ de capacidad y se esterilizaron en un autoclave a $121{ }^{\circ} \mathrm{C}$ y $1,1 \mathrm{Kg} \mathrm{cm}^{-2}$ por 15 minutos. En el interior de la cámara de flujo laminar, en cada recipiente se estableció un explante, el recipiente fue cubierto con doble capa de papel aluminio y sellado con Nescofilm®. Los cultivos se mantuvieron en estantes metálicos con suministro de luz fría fluorescente (40 $\mu$ mol $\mathrm{m}^{-2} \mathrm{~s}^{-2}$. Al final del período de cultivo se registró para cada tratamiento el número de nuevos tallos, hojas y raíces por cada explante establecido, así como el número de microtúberos producidos y el valor de masa fresca de los mismos. Los datos registrados fueron analizados con un análisis de varianza con base en el modelo estadístico $Y_{i j}=\mu+$ $\beta_{\mathrm{i}}+\mathrm{T}_{\mathrm{i}}+(\beta \mathrm{T})_{\mathrm{ij}}+\mathrm{e}_{\mathrm{ij}} ;$ donde " $\mu$ " corresponde al promedio general, $\beta_{i}$ corresponde al efecto de las dosis de sacarosa, $T_{j}$ corresponde al efecto de las dosis de $A B A$ y $e_{\mathrm{ijn}}$ corresponde al efecto del error experimental. Los promedios fueron separados con la prueba de separación de medias de Duncan $(\alpha=0,05)$.

\section{RESULTADOS Y DISCUSIÓN}

\section{Crecimiento de plantas in vitro}

Los registros permitieron observar el desarrollo de plántulas completas a partir de los explantes establecidos en medio de cultivo suplido con los diferentes tratamientos en estudio. Los datos obtenidos muestran una tendencia a una reducción en la formación del número de tallos y hojas en las plantas obtenidas a partir de los explantes cultivados en medios suplidos con ABA; contrariamente, se observa que la adición de $90 \mathrm{~g} \mathrm{~L}^{-1}$ de sacarosa produjo plantas con un incremento significativo $(\operatorname{Pr}<0,05)$ en el número de tallos, hojas y raíces, independientemente de la dosis de $A B A$ presente en el medio. Adicionalmente, de forma general se pudo observar que los menores valores para estas variables se registraron, cuando las plantas fueron cultivadas en presencia de $30 \mathrm{~g} \mathrm{~L}^{-1}$ de sacarosa (Tabla 1).

Estudios realizados en plantas tuberosas de los géneros Dioscorea (Chen et al. 2007) y Solanum (Prat 2010) reportan que la adición de sacarosa al medio de cultivo actúa como inductor en la formación de estructuras vegetativas tales como tallos, raíces, hojas y túberos, Ncube et al. (2014) demostraron que un aumento en el contenido de sacarosa en el medio incrementa la tasa relativa de crecimiento de cultivos in vitro de Cyranthus guhrieae L. respuesta que fue potencializada con la adición diferencial y 
progresiva de $\mathrm{N}$ en el medio de cultivo. Estos resultados soportan los datos obtenidos en el presente estudio donde los promedios de tallos, hojas y raíces aumentó significativamente $(P r<$ 0,05 ) en los el medio de cultivo con altas concentraciones de sacarosa $\left(90 \mathrm{~g} \mathrm{~L}^{-1}\right)$ y en ausencia de ABA, lo cual puede explicarse por el papel antagónico que ha sido reportado entre auxinas y $\mathrm{ABA}$ en cultivo de plantas en condiciones in vitro (Hayashi et al. 2014).

El efecto de sacaraosa en la organogénesis de ciertas especies cultivadas in vitro ha sido evidenciado en ciertos estudios, Wang et al (2015) reportaron la influencia inequívoca de sacarosa en la formación de raíces en plantas de Lupinus albus cultivadas in vitro, y relacionan la participación de genes que codifican por la expresión de fosfoenolpiruvato carboxilasa, ácido secretor fosfatasa y factores MATE como responsables de la señal inductora. En otro estudio realizado en cultivos in vitro de Rosa hybrida se comprobó que el inicio y sostenimiento del crecimiento de los brotes in vitro depende de la disponibilidad y dosis de sacarosa presente en el medio y que esta se relaciona a su vez con la activación de genes responsables de la síntesis de auxinas, una hormona del crecimiento vegetal, como RhTAR1, RhYUC1, RhPIN1 y el promotor PIN1 en la membrana plasmática.

\section{Inducción de microtúberos}

Aunque se pudo observar el crecimiento y desarrollo de plantas a partir de los explantes establecidos en todos los medios suplidos con los tratamientos en evaluación; la formación de microtúberos no ocurrió de forma generalizada en todos los tratamientos. En las plantas que desarrollaron microtuberos, estos crecieron exclusivamente en la base del tallo (Figura 1).

La formación de microtubérculos se observó en plantas cultivadas en medio con dosis altas $\left(2,0 \mathrm{mg} \mathrm{L}^{-1}\right.$ y $\left.3,0 \mathrm{mg} \mathrm{L}^{-1}\right)$ de ABA, mientras que en aquellas cultivadas en medio con $\leq 1 \mathrm{mg}$ $\mathrm{L}^{-1}$ de $\mathrm{ABA}$ no se formaron estas estructuras. El mayor porcentaje de microtuberización (65\%) se observó en las plantas cultivadas en el medio MS con $60 \mathrm{~g} \mathrm{~L}^{-1}$ de sacarosa y 3,0 $\mathrm{mg} \mathrm{L}^{-1} \mathrm{ABA}$, seguido por las plantas cultivadas en los medios que contenían $60 \mathrm{~g} \mathrm{~L}^{-1}$ de sacarosa y $2,0 \mathrm{mg} \mathrm{L}^{-1}$ ABA (13\%) y las cultivadas en presencia de $30 \mathrm{~g}$ $\mathrm{L}^{-1}$ de sacarosa con 2,0 mg L-1 $\mathrm{ABA}$, y $90 \mathrm{~g} \mathrm{~L}^{-1} \mathrm{de}$ sacarosa combinada con $3,0 \mathrm{mg} \mathrm{L}^{-1} \mathrm{ABA}(11 \%)$ (Figura 2).

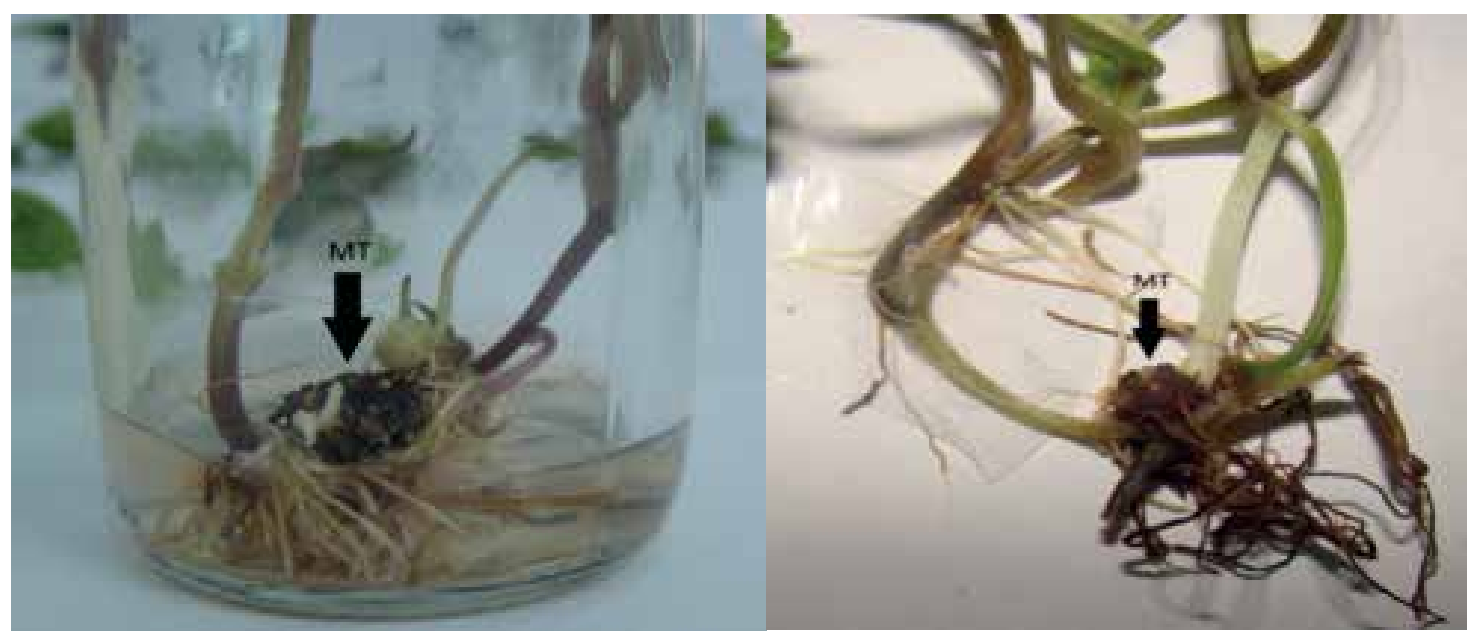

Figura 1: Plantas de ñame in vitro con formación de microtúberos en la base del tallo (MT). 
Suárez et al. - ABA y sacarosa en formación de microtúberos

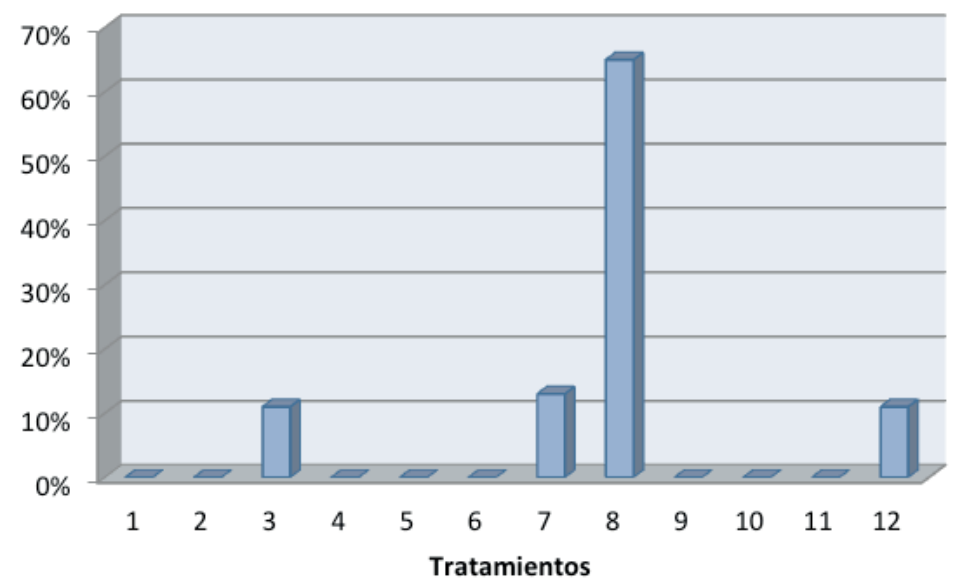

Figura 2: Porcentaje de inducción de microtúberos de ñame en presencia de diferentes combinaciones de sacarosa $\left(\mathrm{g} \mathrm{L}^{-1}\right)$ / ácido abscísico (mg L-1): 1: 30/0,0; 2: 30/1,0; 3: 30/2,0; 4: 30/3,0; 5: 60/0,0; 6: 60/1,0; 7: 60/2,0; 8: 60/3,0; 9: 90/0,0; 10: 90/1,0; 11: 90/2,0; 12: 90/3,0.

Los resultados muestran que existieron diferencias significativas en el número de túberos formados in vitro bajo el efecto de los tratamientos aplicados $(\operatorname{Pr}<0,05)$. La prueba de separación de medias de Duncan mostró que el tratamiento consistente de $60 \mathrm{~g} \mathrm{~L}^{-1}$ de sacarosa y $3,0 \mathrm{mg} \mathrm{L}^{-1}$ de $\mathrm{ABA}$ indujo el mayor número promedio de microtúberos en las plantas cultivadas in vitro (5), seguido por igual por los tratamientos con $60 \mathrm{~g} \mathrm{~L}^{-1}$ de sacarosa y 2,0 $\mathrm{mg} \mathrm{L}^{-1}$ de ABA (1), el consistente de $30 \mathrm{~g} \mathrm{~L}^{-1}$ de sacarosa y $2,0 \mathrm{mg} \mathrm{L}^{-1}$ de $\mathrm{ABA}(1)$, y el de $90 \mathrm{~g}$ $\mathrm{L}^{-1}$ de sacarosa y $3,0 \mathrm{mg} \mathrm{L}^{-1}$ de $\mathrm{ABA}(1)$, mientras que las combinaciones de $30 \mathrm{~g} \mathrm{~L}^{-1}$ de sacarosa con 3,0 mg L-1 de ABA y $90 \mathrm{~g} \mathrm{~L}^{-1}$ de sacarosa con 3,0 mg $\mathrm{L}^{-1}$ de $A B A$ no evidenciaron la formación de estructuras tuberosas.

Los resultados observados en el presente estudio donde se pudo observar la inducción de microtúberos solo en plantas cultivadas en presencia de cantidades relativamente altas de ABA y el incremento significativo del número de microtúberos cuando los explantes fueron cultivados con la adición en el medio de 3,0 $\mathrm{g} \mathrm{L}^{-1}$ de $\mathrm{ABA}$, sugiere una posible dependencia de las plantas de ñame a la presencia de este regulador para formar microtúberos en condiciones in vitro. La formación de microtúberos, y otros órganos de reserva, en plantas en condiciones in vitro es resultado de diversos factores de naturaleza genética que puede verse modificados por las condiciones de cultivo y fisiología de la planta (Guo et al. 2010; Bansal et al. 2012; Badr et al. 2015). Para el caso específico de la participación de ABA en la formación de túberos in vitro, esta se ha atribuido a la acción metabólica de ABA en la acumulación de reservas en ciertos órganos de la planta donde estimula la absorción de sacarosa incrementando de esta forma los niveles de acumulación de almidón en los sitios de reserva (Karmoker y Van Steveninck 1979; Schussler et al. 1984; Hu et al. 2012; Lema-Ruminska et al. 2013).

En estudios previos, Ng (1988) reportó la importancia de la sacarosa para inducir la formación de microtúberos en plantas $D$. rotundata cultivadas in vitro; no obstante, en el presente estudio, las plantas cultivadas en diferentes niveles de sacarosa fallaron en la inducción de microtúberos a menos que el medio de cultivo fuera adicionado con $\geq 2,0 \mathrm{mg}$ $\mathrm{L}^{-1}$ de $\mathrm{ABA}$. Esto sugiere que la sacarosa por sí sola no es suficiente para inducir la formación de microtúberos y que requiere de la acción de reguladores de crecimiento, $A B A$ en este 
caso, para ejercer su función inductora; o si por el contrario la sacarosa en si no participa directamente en la formación de las estructura y en su lugar actúa como un potencializador del efecto de los reguladores de crecimiento. Estudios realizados con plantas de Dioscorea cayenensis y $D$. rotundada evidenciaron la correlación entre los altos niveles de sacarosa (8\%) con diferentes niveles de ácido jasmónico (JA) para aumentar la inducción de microtúberos en condiciones in vitro, lo cual ratifica efecto potencializador de la sacarosa en presencia del regulador de crecimiento para mejorar los niveles de inducción (Olivier et al. 2012; Dai et al. 2014). El efecto inductor de reguladores de crecimiento en la formación de órganos de reserva y de propagación en condiciones in vitro en combinación o ausencia de sacarosa ha sido reportado en otras especies vegetales (Deroles et al. 2010; Rayirath et al. 2011; López 2015).

\section{Contenido de masa fresca de los microtúberos}

El contenido de masa fresca ha sido reportado como una variable de gran importancia debido a su relación con la brotación, supervivencia y las características morfológica de la planta, observándose mayores índices de supervivencia y calidad de las plantas obtenidas cuando se obtienen microtúberos de mayor tamaño (Cabrera et al. 2011).
Estudios realizados en otras especies tuberosas han asociado las altas dosis de sacarosa en el medio con mayor tamaño de los microtúberos y mejor desempeño de plantas micropropagadas transferidas a condiciones ex vitro (Badr et al. 2015). Aunque en el presente estudio no se encontraron diferencias significativas entre los valores de masa fresca de los microtúberos obtenidos a partir de las plantas cultivadas en presencia de los diferentes tratamientos $(\operatorname{Pr}>0,05)$, los datos colectados mostraron que los mayores valores para esta variable se presentaron cuando los microtúberos crecieron a partir de las plantas cultivadas en medio con $90 \mathrm{~g} \mathrm{~L}^{-1}$ de sacarosa y 3,0 $\mathrm{mg} \mathrm{L}^{-1}$ de ABA, seguido por las plantas que se cultivaron en los medios suplidos con $60 \mathrm{~g} \mathrm{~L}^{-1}$ sacarosa y 3,0 $\mathrm{mg} \mathrm{L}^{-1} \mathrm{ABA}$, mientras que los menores valores ocurrieron cuando las plantas se cultivaron en medio con $30 \mathrm{~g} \mathrm{~L}^{-1}$ de sacarosa y 2,0 mg $\mathrm{L}^{-1} \mathrm{ABA}$ y $60 \mathrm{~g} \mathrm{~L}^{-1}$ de sacarosa y $2,0 \mathrm{mg} \mathrm{L}^{-1} \mathrm{de}$ ABA (Tabla 1). Este resultado puede tener una explicación en el suministro de sacarosa como fuente de carbohidrato, y la presencia de ABA como un regulador de crecimiento vegetal que contribuye con el crecimiento de los órganos de reserva promoviendo la acumulación de almidón (Rook et al. 2006; Sharma et al. 2004; Hu et al. 2012); por lo que al existir mayor disponibilidad de estos componente

Tabla 1. Efecto de las diferentes concentraciones de sacarosa y ácido abscísico (ABA) sobre las características de las plantas de Dioscorea rotundata cultivadas in vitro, los microtúberos inducidos y su masa fresca.

\begin{tabular}{|c|c|c|c|c|c|c|c|c|c|c|c|c|}
\hline \multirow{3}{*}{ Variable } & \multicolumn{12}{|c|}{ Sacarosa $\left(\mathrm{mg} \mathrm{L}^{-1}\right)$} \\
\hline & \multicolumn{4}{|c|}{$30\left(\mathrm{mg} \mathrm{l}^{-1}\right) \mathrm{ABA}$} & \multicolumn{4}{|c|}{$60\left(\mathrm{mg} \mathrm{L}^{-1}\right) \mathrm{ABA}$} & \multicolumn{4}{|c|}{$90\left(\mathrm{mg} \mathrm{L}^{-1}\right) \mathrm{ABA}$} \\
\hline & $\mathbf{0}$ & 1 & 2 & 3 & $\mathbf{0}$ & 1 & 2 & 3 & $\mathbf{0}$ & 1 & 2 & 3 \\
\hline Tallos (No) & $10,1 a^{*}$ & 4,0 de & 3,6 ed & $2,6 \mathrm{e}$ & 9,7 bc & $3,7 \mathrm{de}$ & $3,3 \mathrm{e}$ & 6,0 cde & 15,3 a & $7,4 \mathrm{bcd}$ & 6,0 cde & 3,9 de \\
\hline Raíces (No) & $4,3 \mathrm{c}$ & $4,0 \mathrm{c}$ & $4,0 \mathrm{c}$ & $3,4 \mathrm{c}$ & $4,1 \mathrm{c}$ & 4,9 bc & $5,7 \mathrm{bc}$ & 8,0 abc & $10,5 a b$ & 8,0 abc & $12,0 \mathrm{a}$ & $8,8 \mathrm{abc}$ \\
\hline Hojas (no) & $8,7 \mathrm{ab}$ & $3,85 \mathrm{~cd}$ & $3,43 \mathrm{~cd}$ & $3,1 \mathrm{~d}$ & $10,1 \mathrm{ab}$ & $4,9 \mathrm{~cd}$ & $3,5 \mathrm{~cd}$ & 6,7 bcd & $11,1 \mathrm{a}$ & $7,1 \mathrm{dc}$ & $4,8 \mathrm{~cd}$ & $4,3 \mathrm{~cd}$ \\
\hline Microtúberos (No) & 0,0 & 0,0 & $1 \mathrm{~b}$ & 0,0 & 0,0 & 0,0 & $1 \mathrm{~b}$ & 5 & 0,0 & 0,0 & 0,0 & $1 \mathrm{~b}$ \\
\hline Masa fresca (g) & $-* *$ & - & $0,004 \mathrm{~b}$ & - & - & - & $0,04 \mathrm{~b}$ & $0,16 \mathrm{a}$ & - & - & - & $0,06 \mathrm{~b}$ \\
\hline
\end{tabular}

*Valores con la misma letra no son diferentes de acuerdo con la prueba de separación de medias de Duncan $(\alpha=0,05)$, ** $(-)=$ No hubo lectura de datos. 
en el medio de cultivo, la incorporación en la planta en forma de almidón es mayor mediante un desarrollo coordinado de la planta y sus órganos con la disponibilidad de nutrientes en su entorno (Ondo 2009).

\section{CONCLUSIÓN}

La adición de sacarosa y ácido abscísico (ABA) en diferentes cantidades en el medio de cultivo afecta significativamente el crecimiento in vitro de las plantas de ñame (Dioscorea rotundata Poir.) y la producción de microtúberos, observándose que la inducción y el crecimiento de los microtúberos de ñame (Dioscorea rotundata Poir.) ocurren solo cuando el medio es adicionado con ABA y sacarosa, aunque el mayor número de microtúberos ocurrió cuando los explantes fueron cultivados en presencia de $60 \mathrm{~g} \mathrm{~L}^{-1}$ de sacarosa y 3,0 $\mathrm{mg} \mathrm{L}^{-1}$ de ácido abscísico.

\section{REFERENCIAS}

Acedo, V. Arradaza C. and Atilano, C. 2007. Microtuber production in Dioscorea alata L. variety "VU-2" as affected by growth regulators, Journal of Root Crops, 33(2):88-96.

Anike, F. Konan, K. Olivier, K. and Dodo, H. 2012. Efficient shoot organogenesis in petioles of yam (Dioscorea spp), Plant Cell, Tissue and Organ Culture 111(3):303-313.

Badr, A. Angers, P. and Desjardins, Y. 2015. Comprehensive analysis of in vitro to ex vitro transition of tissue cultured potato plantlets grown with or without sucrose using metabolic profiling technique, Plant Cell Tissue and Organ Culture 122(2): 491-508.

Balogun, M. 2009. Microtubers in yam germplasm conservation and propagation: The status, the prospects and the constraints, Biotechnology and Molecular Biology Reviews, 4(1):1-10.

Bansal, A. Kumari, V. Taneja, D. Sayal, R. and Das, N. 2012. Molecular cloning and characterization of granule-bound starch synthase I (GBSSI) alleles from potato and sequence analysis for detection of cisregulatory motifs, Plant Cell Tissue and Organ Culture 109(2): 247-261.

Bruno, M. Beyer, P. and Al-Babili, S. 2015. The potato carotenoid cleavage of B-ionone ring-containing carotenes and nonepoxidated xanthophylls, Archives of Biochemistry and Biophysics 572:126-33.

Cabrera, M. Gómez, R. Espinosa, E. López, J. Medero, V. Basail, M. and Arletys, A. 2011. Yam (Dioscorea alata L.) microtuber formation in Temporary Immersion System as planting material, Biotecnología Aplicada 28: 268-271.

Cereda, M. 2002. Importancia, modo de consumo e perspectiva para raíces e tuberculos horticolas no Brasil, In: Carmo, C,A, Inhame e taro: sistema de produção familiar, Vitoria: Instituto Capixaba de pesquisa, asistencia Técnica e Extensao Rural, Brasil, p23-32.

Chen, F. Fu, Y. Wang, D. Gao, X. and Wang, L. 2007. The effect of plant growth regulators and sucrose on the micropropagation and microtuberization of Dioscorea nipponica Makino, Journal of Plant Growth Regulator 26(1):38-45.

Dai, Z. Meddar, M. Renaud, C. Merlin, I. Hilbert, G. Delrot, S. and Gomès, E. 2014. Long-term in vitro culture of grape berries and its application to assess the effects of sugar supply on anthocyanin accumulation, Journal of Experimental Botany 65(16):4665-4677. 
Deroles, S. Seelye, J. Javellana, J. and Mullan, A. 2010. In vitro propagation of Sandersonia aurantiaca Hook using thidiazuron, Plant Cell Tissue and Organ Culture 102(1): 115-119.

Guo, L. Yu, L. Fan, Y. Lu, Neng, Yin, M. Zhang, F. and Yang, Q. 2010. Cloning and characterization of a potato TFL1 gene involved in tuberization regulation, Plant Cell Tissue and Organ Culture103(1): 103-109.

Hayashi, Y. Takahashi, K. Inoue, S. and Kinoshita, T. 2014. Abscisic acid suppresses hypocotyl elongation by dephosphorylating plasma membrane $\mathrm{H}(+)$-ATPase in Arabidopsis thaliana, Plant Cell Physiology 55(4): 845-853.

Hu, Y. Li, Y. Zhang, J. Liu, H. Tian, M. and Huang, Y. 2012. Binding of $A B I 4$ to a CACCG motif mediates the ABA-induced expression of the $\mathrm{ZmSSI}$ gene in maize (Zea mays L.) endospem, Journal of Experimental Botany 63(16): 5979-5989.

Jang-Ho. 2015. The laccase promoter of potato confers strong tuber-specific expression in transgenic plants, Plant Cell Tissue and Organ Culture 120(1):57-68.

Jean, M. and Cappodocia, M. 1991. In vitro tuberization in Dioscorea alata L. "Brazo fuerte" y "Florido" y D. abbyssinica. Hoch. Plant Cell Tissue and Organ Culture 26:147-152.

Karmoker, J. and Van Steveninck, R. 1979. Stimulation of volume flow and ion flux by abscisic acid in excised root systems of Phaseolus vulgaris L. CV Redland Pioneer, Physiologia Plantarum 141(1):37-43.

Lema-Ruminska, J. Goncerzewicz, K. and Gabriel, M. 2013. Influence of AbscisicAcid and Sucrose on Somatic Embryogenesis in
Cactus Copiapoa tenuissima Ritt, Forma mostruosa, The Scientific World Journal 2013ID513985 7p.

López, O. 2015. Inducción de estructuras vegetativas de caña flecha (Gynerium sagitatum Aubl.) in vitro, Tesis Licenciado en Ciencias Naturales, Universidad de Córdoba, Montería, 40p.

McKoy, M. Thomas, P. Asemota, H. Omoruyi, F. and Simon, O. 2014. Effects of Jamaican bitter yam (Dioscorea polygonoides) and diosgenin on blood and fecal cholesterol in rats, Journal of Medicine Food 17(11): 1183.

Muñiz-Garcia, M. Stritzler, M. and Capiati, D. 2014. Heterologous expression of Arabidopsis ABF4 gene in potato enhances tuberization through ABA-GA crosstalk regulation, Planta 239(3): 615631.

Murashige, T. and Skoog, F. 1962. A revised medium for proper growth and bioassays with tobacco tissue culture, Physiologia Plantarum 15:473-497.

Ncube, B. Finnie, J. and Van, J. 2014. Carbonnitrogen ratio and in vitro assimilate partitioning patterns in Cyrtanthus guthrieae L. Plant Physiology and Biochemistry 74:246-254.

Ng, S. 1988. In vitro tuberization in white yam (Dioscorea rotundata Por.), Plant Cell Tissue and Organ Culture14:121-128.

Olivier, K. Honan, K. Anike, F. Agbo, G. and Dodo, H. 2012. In vitro induction of minitubers in yam (Dioscorea cayenensis - D. rotundata complex), Plant Cell Tissue and Organ Culture 109(1):179-189.

Ondo, P. Kevers, C. and Dommes, J. 2009. Effects of reducing sugar concentration 
on in vitro tuber formation and sprouting in yam (Dioscorea cayenensis - D. rotundata complex), Plant Cell Tissue and Organ Culture 99:55-59.

Perea, M. and Buitrago G. 2000. Aplicación de la Biotecnología Agrícola al cultivo del Ñame, En: producción de semillas por Biotecnología, Universidad Nacional de Colombia, Bogotá D.C. Colombia, p1719.

Prat, S. 2010. Hormonal and day length control of potato tuberisation, Plant Hormones, Madrid, p574-596.

Rayirath, U. Lada, R. Caldwell, C. Asiedu, S. and Sibley, K. 2011. Role of ethylene and jasmonic acid on rhizome induction and growth in rhubarb (Rheum rhabarbarum L.), Plant Cell Tissue and Organ Culture 105(2): 253-263.

Rêgo, T. Ash, L. Pessoa, L. Feijo, M. Leite, J. Dos santos Ade, S. Da Costa, C. and Boaventura, G. 2014. The intake of yam (Dioscorea bulbifera Linn.) attenuated the hyperglycemia and the bone fragility in female diabetic rats. Nutrition Hospital 29:370.

Rook, F. Hadingham, S. Li, Y. and Bevan, M. 2006. Sugar and ABA response pathways and the control of gene expression, Plant Cell and Environment 29:426-434.

Salazar, R. and Beltrán, J. 2003. Microtuberización en ñame (Dioscorea alata L.) var. "Pico de Botella", Revista Colombiana de Biotecnología 4(2):2732.

Schussler, J. Brenner, M. and Brun, W. 1984. Abscisic Acid and Its Relationship to Seed Filling in Soybeans, American Society of Plant Biologists, Plant Physiology 76(2): 301-306.
Scott, G. Rosegrant, M. and Ringler, C. 2006. Roots and tubers for the 21st Century: Trends, projections, and policy options, Food Agriculture and the Environment Discussion 31, Washington, DC: International Food Policy Research Institute (IFPRI) and International Potato Center (CIP), Lima, p1-63.

Sharma, P. Pandey, A. Bhattacharya, A. Nagar, P. and Ahuja, P. 2004. ABA associated biochemical changes during somatic embryo development in Camellia sinensis (L.) O. Kuntze. Plant Physiology 161:1269-1276.

Suárez, I. Torres, L. and Litz R. 2011. Somatic embryogenesis in yam (Dioscorea rotundata), Revista Facultad Nacional de Agronomía Medellín 64(2):6037-6042.

Tamiru, M. Becker, H. and Maass, B. 2008. Diversity, distribution and management of yam landraces (Dioscorea spp.) in Southern Ethiopia, Genetic Resources Crop Evolution 55:115-131.

Wang, Z. Shen, J. Ludewing, U. and Neumann, G. 2015. A re-assessment of sucrose signaling involved in cluster-root formation and function in phosphatedeficient white lupin (Lupinus albus), Physiologia plantarum 154(3):407-419.

Yan, H. Yang, L. and Li, Y. 2011. Axilliary shoot proliferation and tuberization of Dioscorea fordii Prainet Burk. Plant Cell Tissue and Organ Culture 154(2): 193198. 